\title{
What do we know about men's help-seeking and health service use?
}

\author{
James A Smith, Annette Braunack-Mayer and Gary Wittert
}

I $\mathrm{n}$ the Western world, the health of men is poorer than that of women, mortality rates are higher and men use health services less often than women, even when reproductive services have been accounted for. ${ }^{1-5}$ In fact, being male is a significant risk factor for early mortality in developed countries. ${ }^{6,7}$ Before age 50 years, for every 10 premature female deaths, 16 men die prematurely, predominantly from cardiovascular disease, accidents, suicide and neoplasms. ${ }^{6}$ Men are also more susceptible than women to mortality related to climate. ${ }^{8}$

Rates of morbidity and mortality are useful in establishing that men's health should be monitored more closely. Men's help-seeking behaviour and use of health services deserves increased attention. Although men's help-seeking is known to be problematic, there is scant research to suggest how and why this is so. ${ }^{4,9}$ Rather, it is assumed that men are less interested in or concerned about their health, and therefore may be less likely to seek help for healthrelated problems.

Help-seeking is considered to be the recognition of a health concern together with the range of actions that result, one of which is health service utilisation. The interchangeable use of terms such as doctor, health service, health service provider and health care system make comparisons between studies complex. Nevertheless, regardless of definitions, men consult doctors (specifically general practitioners) less often than women do. ${ }^{1-3,10-15}$ More generally, men use all services within the health care system to a lesser extent than women, ${ }^{14,16}$ and women have a greater acceptance of, and consequently use of, health care services. ${ }^{17,18}$

Men are often blamed for being poor consumers of health services, and are thus seen to be victims of their own behaviour. $2,3,9,19,20$ We need a different view to that which positions men as "behaving badly". 21,22 Various commentators have offered suggestions to counteract victim blaming, including ones related to using a gender-relations approach, a population health approach, a salutogenic approach and/or a social marketing approach. ${ }^{13,22-24}$ Little empirical evidence using these approaches has emerged in the Australian context. Equally noteworthy is that the skills of health service providers can sometimes fail men. ${ }^{11,25-27}$ Policy advocates have also indicated that inadequate attempts to develop state and national men's health policies and lack of available resources, for both researchers and practitioners, are to blame for the poorer health status of men. ${ }^{28}$ However, it is unproductive to apportion blame.

In this article, we explore why men are viewed as reluctant to seek help and why they use health services less, and the consequences this has for health service delivery and the development of programs tailored for men.

University of Adelaide, Adelaide, SA.

James A Smith, PhD Candidate, Departments of Public Health and Medicine; Annette Braunack-Mayer, PhD, Senior Lecturer, Department of Public Health; Gary Wittert, MB BS, FRACP, Head, Department of Medicine.

Reprints will not be available from the authors. Correspondence: Professor G Wittert, Level 6, Eleanor Harrald Building, Frome Rd, Royal Adelaide Hospital, Adelaide, SA 5005. gary.wittert@adelaide.edu.au

\section{ABSTRACT}

- Men seek help and use health services less frequently than women do.

- Men's help-seeking practices and health service use are complex issues involving biological, psychological and sociological considerations.

- Most discussion on men's help-seeking positions them as reluctant consumers or "behaving badly" with respect to their health.

- Few studies have explored whether health service providers are equipped to deal with men's health issues appropriately.

- The current health system appears not to be tailored to meet the health needs of men.

- Better collaboration is required across disciplines, to further investigate men's health using both qualitative and quantitative research methods.

MJA 2006; 184: 81-83

\section{Patterns of help-seeking: implications for provision of health care}

There are a number of interesting observations relating to the pattern of help-seeking and health service utilisation by men. First, the initial approach by men for seeking help for health-related issues tends to be indirect. ${ }^{1}$ Men tend to view their partners and friends as a primary resource for help. ${ }^{24}$ Innovative ways to engage men in preventive health discussion have been offered, particularly in relation to environments where men congregate, such as sporting venues, workplaces and pubs. ${ }^{17,22,24}$

In circumstances where men do seek primary health care, they are more likely than women to focus on physical problems and are less likely to disclose mental and emotional problems. ${ }^{13}$ Men also appear to spend less time with physicians during their health visits than women, and receive less advice from physicians about changing risk factors for disease, particularly during general checkups. ${ }^{2}$ Based on the perspectives of family physicians, a number of systematic barriers that prevent men from seeking help from health services have been identified. These include lack of time, poor access opportunities, having to state the reason for a visit, and the lack of a male care provider. ${ }^{1}$

These observations highlight two significant issues. First, consideration should be given to how health practitioners behave when interacting with men. Second, we need to consider the personal experiences of men when they speak of their health. Therefore, it is important to understand how help-seeking behaviour among men has been explained throughout existing scholarship.

\section{Factors determining help-seeking and health service use among men}

Two groups of factors have been proposed to account for the patterns in men's help-seeking behaviour and health service use: sociocultural and biological factors. These factors do not operate 
independently of each other and, in the concluding paragraph of this section we suggest how they can be viewed together.

The social construction of masculinity acts as an important influence on health and illness, and one that may both prescribe and limit men's lives. ${ }^{1-4,9,13,15,22,25,26}$ Sociologists have implied that specific behaviour associated with traditional forms of masculinity is likely to be hazardous to men's health. ${ }^{29}$ Dominant masculine cultures and values may negatively affect patterns of illness and men's experiences and behaviour. ${ }^{15}$ Stoicism and suppression of emotion, for example, are values often associated with masculine gender role socialisation. ${ }^{9}$ Adherence to patriarchal masculine characteristics, such as superiority, independence, self-reliance and dominance, may also act as a barrier to men appropriately accessing and using health services. ${ }^{9,16,20,22,25,29,30}$

Men are also influenced by cultural stereotypes to ignore screening and preventive health care, and to delay help-seeking for symptoms. ${ }^{3,9,19}$ This results in men underutilising health services aimed at early intervention. 9,20,31 Subsequently, poor health-seeking behaviour results in poor health care use among men, which limits their access to information and restricts opportunities for health promotion interaction and primary care use. ${ }^{17,31}$

The social factors that shape men's help-seeking behaviour have been explained above, yet much research in this area fails to address biology. Male biology needs to be considered as a fundamental factor in understanding men's health behaviour. Traditionally, men's health has been constituted by diseases of the male reproductive organs - primarily prostate and testicular health, but has more recently focused on erectile dysfunction. ${ }^{9,12,14}$ Although these health concerns are specific to the biology of men, the margins of difference between both men's and women's rates of death and disease, ${ }^{13,28,32}$ may also have a biological basis.

A biologically determinist approach to the differences between men's and women's health experience focuses on structural, physiological and pathological reasons as to why men are more susceptible to a number of diseases than women. ${ }^{21,22,33}$ For example, hormonal differences between men and women have been used, at least in part, to explain variations in male susceptibility to disease. ${ }^{31,34,35}$ Evolutionary pressures toward optimal reproductive outcomes for men have promoted an increase in the prevalence of genes that promote male risk-taking and competitive ability at the expense of decreased investment in repair capacity and disease prevention. ${ }^{36,37}$ The higher rates of fatal and non-fatal accidents for boys have been partially attributed to a particular pattern of motor and cognitive regulation, leading to a misjudgement of risk. $^{38}$

An alternative to the separation of biological and sociocultural approaches to men's health status is to focus on the interplay between sociocultural and biological factors in health and illness. ${ }^{9}$ This is often described as a biopsychosocial understanding, and it may provide a more useful approach in addressing the health needs of men more appropriately. ${ }^{9,21}$ Our approach to investigating men's help-seeking and health services use draws on a public health framework that acknowledges the complex ways in which physiological differences are shaped by, and shape, culture. The tendency for males to take risks, for example, is associated with higher rates of violence, fatal accidents and the use of alcohol or illicit drugs. ${ }^{38}$ The reasons why young men, particularly, are risktakers involve biological factors such as age and hormonal influences, but these factors are mediated by cultural pressures to present a particular masculine identity to the world. The extent to which this behaviour is related to the tendency to delay or avoid help-seeking, and how this behaviour is shaped or can be modified by socialisation, remains to be determined and ought to be a key focus for research. Nevertheless, few studies have explored men's help-seeking from a public health perspective, particularly using qualitative methods like those that are now widespread in women's health studies. ${ }^{9,16,21}$

\section{Conclusion}

It is clear that men's help-seeking and health service use is problematic, but it is unhelpful to adopt a stance that inherently blames and therefore attempts to "re-educate" the consumer, particularly when there is limited evidence to guide effective program development and appropriate intervention strategies. It cannot be assumed that current health services meet the needs of men, or that health service providers are appropriately trained to address the specific health needs of men. We need to better understand how to deliver preventive health messages and provide health care in a gender appropriate manner. Further to this argument, discipline-specific research findings offer a partial, rather than complete picture for adequately addressing men's health concerns. Collectively, these perspectives can provide a holistic view of men's health, which encompasses biological, psychological and social viewpoints.

Recognising the value of adopting a public health approach to address these disciplinary boundaries will assist in improving the health of Australian men. Further data from both quantitative and qualitative studies are required, using multidisciplinary and interdisciplinary approaches and involving all stakeholders., ${ }^{9,18}$

\section{Acknowledgements}

We acknowledge Professor Janet Hiller and Dr Megan Warin for their constructive comments and feedback on earlier drafts of this article. We also wish to acknowledge the financial support of the Florey Medical Research Fund and the University of Adelaide, as well as the commitment and efforts of the research team and collaborators involved in the Florey Adelaide Male Ageing Study (FAMAS).

\section{Competing interests}

None identified.

\section{References}

1 Tudiver F, Talbot Y. Why don't men seek help? Family physicians' perspectives on help-seeking behaviour in men. J Fam Pract 1999; 48: 4752.

2 Courtenay W. Constructions of masculinity and their influence on men's well-being: a theory of gender and health. Soc Sci Med 2000; 50: 13851401.

3 Courtenay W. Behavioural factors associated with disease, injury, and death among men: evidence and implications of prevention. J Mens Stud 2000; 9: 81-142.

4 Mansfield A, Addis M, Mahalik JR. Why won't he go to the doctor?: the psychology of men's help seeking. Int J Mens Health 2003; 2: 93-109.

5 Porter L, Ku L. Use of reproductive health services among young men, 1995. J Adolesc Health 2000; 27: 186-194.

6 Kruger D, Nesse R. Sexual selection and the male : female mortality ratio. Evol Psychol 2004; 2: 66-85.

7 Garilov L, Garilova N. The biology of lifespan: a quantitative approach. Chur, Switzerland: Harwood Academic Publishers, 1991.

8 Rau R, Doblhammer G. Seasonal mortality in Denmark: the role of sex and age. Demographic Res 2003; 9: 197-222. 
9 Lee C, Owens G. The psychology of men's health. Buckingham: Open University Press, 2002.

10 Purcell H. Time to reverse the descent of man. Lancet 1995; 346: 240.

11 Burkitt G. Strategies for dealing with men in general practice. Aust Fam Physician 1999; 28: 773-774.

12 Smith A, Mischewski A, Gifford S. 'They just treat you as a number': aspects of men's experience in a Melbourne sexual health service. Venereology 1999; 12: 15-19.

13 Schofield T, Connell R, Walker $L$, et al. Understanding men's health and illness: a gender-relations approach to policy, research, and practice. J Am Coll Health 2000; 48: 247-256.

14 Chapple A, Ziebland S. Prostate cancer: embodied experience and perceptions of masculinity. Sociol Health IIIn 2002; 24: 820-841.

15 Seymour-Smith S, Wetherell M, Phoenix A. "My wife ordered me to come!": a discursive analysis of doctors' and nurses' accounts of men's use of general practitioners. J Health Psychol 2002; 7: 253-267.

16 Lee C, Owens RG. Issues for a psychology of men's health. J Health Psychol 2002; 7: 209-217.

17 Van Buynder P, Smith J. Mortality, myth or mateship gone mad: the crisis in men's health. Health Promot J Austr 1995; 5: 9-11.

18 Sabo D. Men's health studies: origins and trends. J Am Coll Health 2000; 49: 133-142.

19 Cameron E, Bernades J. Gender and disadvantage in health: men's health for a change. Sociol Health IIIn 1998; 20: 673-693.

20 Courtenay W. Engendering health: a social constructionist examination of men's health beliefs and behaviours. Psychol Men Masculinity 2000; 1: 4-15.

21 Macdonald J. The new health for all: environments for health or primary health care is alive and well. Aust J Primary Health Interchange 1999; 5: 6-9.

22 Macdonald J, Crawford D, Gibbs L, Oliffe J. Promoting men's health. In: Moodie R, Hulme A, editors. Hands-on health promotion. Melbourne: I P Communications, 2004

23 Macdonald J, Crawford D. Recent developments concerning men's health in Australia. Aust J Primary Health 2002; 8: 77-82.

24 Denner B. MAN model: health promotion. Aust J Primary Health Interchange 2000; 6: 230-240.

25 Mahalik JR, Good G, Englar-Carlson M. Masculinity scripts, presenting concerns, and help seeking: implications for practice and training. Prof Psychol Res Pr 2003; 34: 123-131.

26 Dalziel A, Leishman J. Stop men losing out in the healthcare stakes: men are reluctant users of health services, particularly primary care. Practice Nurse 2003; 26: 24.

27 Addis M, Mahalik J. Men, masculinity, and the contexts of help seeking. Am Psychol 2003; 58: 5-14.

28 Lumb P. Why is men's health and well-being policy not implemented in Australia? Int J Mens Health 2003; 2: 73-88.

29 Connell R. The men and the boys. Sydney: Allen \& Unwin, 2000.

30 Harrison J, Chin J, Ficarrotto T. Warning: masculinity may be dangerous to your health. In: Kimmel M, Messner M, editors. Men's lives. 3rd ed. Boston: Allyn \& Bacon, 1988.

31 Courtenay W. Key determinants of the health and well-being of men and boys. Int J Mens Health 2003; 2: 1-30.

32 Fletcher R, Higginbotham N, Dobson A. Men's perceived health needs. J Health Psychol 2002; 7: 233-241.

33 Hazzard W. The sex differential in longevity. In: Hazzard W, Endres R, Bierman E, Blass J, editors. Principles of geriatric medicine and gerontology. 2nd ed. New York: McGraw Hill, 1990: 27-37.

34 Sader M, McGrath K, Hill M, et al. Androgen receptor gene expression in leucoytes is hormonally regulated: implications for gender differences in disease pathogenesis. Clin Endocrinol Oxf 2005; 62: 56-63.

35 Muller M, Grobbee J, Thijssen J, et al. Sex hormones and male health: effects on components of the frailty syndrome. Trends Endocrinol Metab 2003; 14: 289-296.

36 Trivers R. Parental investment and sexual selection. In: Campbell B, editor. Sexual selection and the descent of man: 1871-1971. Chicago: Aldine, 1972: 136-179

37 Daly M, Wilson M. Sex, evolution, and behavior: adaptations for reproduction. North Scituate, Mass: Duxbury Press, 1978

38 Kraemer S. The fragile male. BMJ 2000; 321: 1609-1612.

\section{The Medical Journal of Australia SPEOHAL ISSUES FOR 2006}

\section{Do you have an interest in Indigenous health, general practice or men's health?}

The MJA is publishing three special issues with these

themes in 2006 and we're inviting authors to send in their thoughts and best work. High quality research will receive the highest priority, but we're also interested in original commentaries, viewpoints or reviews on hot topics, controversies or innovation in these areas. Readers' suggestions for topics of interest are welcome too.

\section{Indigenous Health \\ Closing date 6 March. \\ Commissioning Editor: Dr Ruth Armstrong}
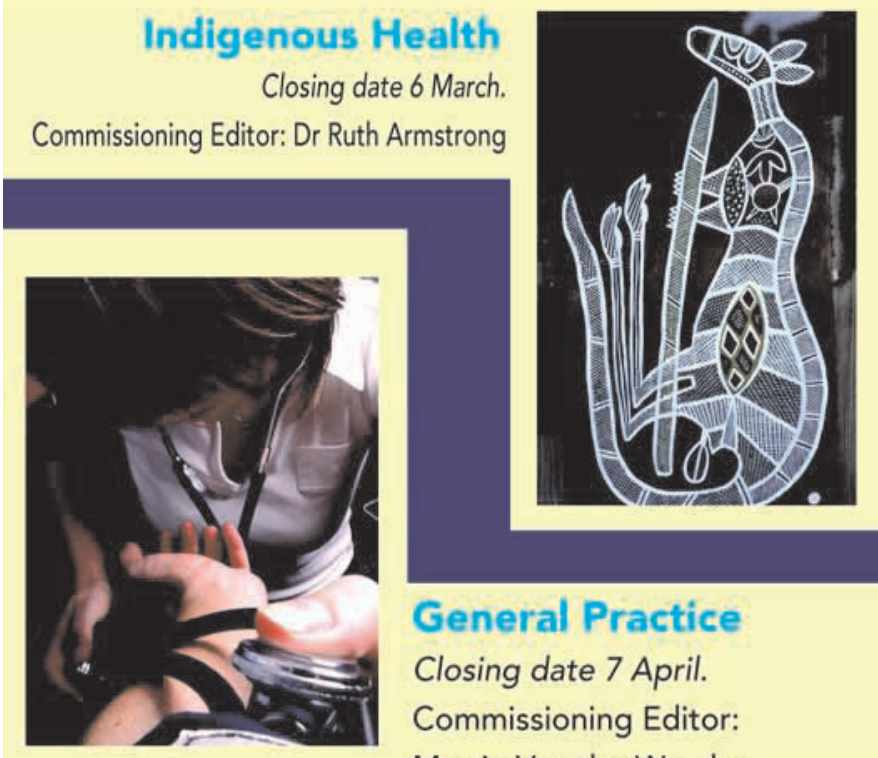

General Practice

Closing date 7 April.

Commissioning Editor:

Martin Van der Weyden

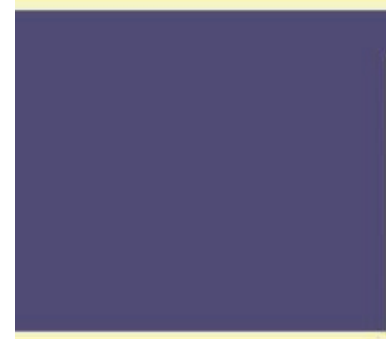

Men's Health

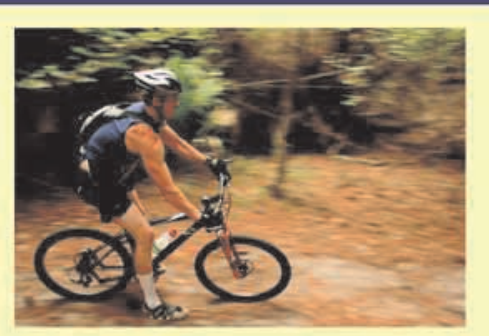

Closing date 31 March. Commissioning Editor: Dr Ann Gregory

If you're not sure whether what you have in mind is suitable, please feel free to discuss it with us first:

Phone: 0295626666 • Email: medjaust@ampco.com.au Please consult our website for advice to authors on article requirements: www.mja.com.au/public/information/instruc.html 